\title{
Amygdalar NMDA Receptors are Critical for New Fear Learning in Previously Fear-Conditioned Rats
}

\author{
Hongjoo Lee and Jeansok J. Kim \\ Department of Psychology, Yale University, New Haven, Connecticut 06520-8205
}

\begin{abstract}
NMDA receptors in the amygdala seem to be critical for fear conditioning in naive rats. Recent spatial-learning studies suggest that previous learning protected animals from the amnesic effect of NMDA antagonists on new learning (of a similar behavioral task). Therefore, the present study examined whether blocking of NMDA receptors in the basolateral nucleus of the amygdala (BLA) prevents new fear learning in previously fearconditioned rats, as measured by freezing behavior. Intra-BLA infusions of the NMDA receptor antagonist DL-2-amino-5phosphonovaleric acid (APV) completely blocked fear conditioning to a tone stimulus in animals that had previously been fear-conditioned to a light stimulus. Similar results were ob-
\end{abstract}

Classical, or Pavlovian, fear conditioning is a type of rapid and potent learning task that requires NMDA receptor activation in the amygdala, a key brain structure implicated in fear learning (Lavond et al., 1993; Davis, 1994; LeDoux, 1994; Maren and Fanselow, 1996) and memory modulation (McGaugh and Introini-Collison, 1987; McGaugh et al., 1996). Infusions of the competitive NMDA receptor antagonist DL-2-amino-5phosphonavaleric acid (APV) into the amygdala (specifically the basolateral/lateral nuclei) block the acquisition of potentiated startle response to both tone and light stimuli (Miserendino et al., 1990; Campeau et al., 1992), the acquisition of conditioned freezing response to the context (Fanselow and Kim, 1994), and learning of inhibitory avoidance tasks (Kim and McGaugh, 1992; Liang et al., 1994). Because NMDA receptors are critical for long-term potentiation (LTP) and long-term depression (LTD) (e.g., the Schaffer collateral/commissural-CA1 pathway in the hippocampus) (for review, see Bear and Malenka, 1994; Collingridge and Bliss, 1995), two forms of relatively long-lasting synaptic plasticity with information storage potentials, it has been postulated that NMDA receptor-dependent synaptic plasticity in the amygdala is involved in fear conditioning (Miserendino et al., 1990; Kim et al., 1991; LeDoux, 1993; Maren and Fanselow, 1996).

Consistent with this view, LTP has been demonstrated in the amygdala, e.g., the external capsure-lateral nucleus of the amygdala (LA) pathway in vitro (Chapman et al., 1990; Chapman and Bellavance, 1992; Li et al., 1995), the internal capsure-LA pathway in vitro (Huang and Kandel, 1997), the auditory thalamus-LA pathway in vivo (Clugnet and LeDoux, 1990), and the subiculum-

\footnotetext{
Received March 27, 1998; revised July 23, 1998; accepted July 27, 1998.

This work was supported by a grant from the Whitehall Foundation. We thank Hugh T. Blair for helpful comments on this manuscript.

Correspondence should be addressed to Jeansok Kim, Department of Psychology, 2 Hillhouse Avenue, Yale University, New Haven, CT 06520-8205.

Copyright (C) 1998 Society for Neuroscience $\quad 0270-6474 / 98 / 188444-11 \$ 05.00 / 0$
}

tained with intra-BLA infusions of APV before contextual fear conditioning in rats that had been fear-conditioned to a different context. Additional experiments showed that intra-BLA APV infusions substantially interfere with the expression and extinction of conditioned fear to tone, light, and context stimuli. Together, these results indicate that NMDA receptors in the BLA are crucial for the encoding of new fear memories (i.e., the formation of specific conditioned stimulus-unconditioned stimulus association), the expression of conditioned fear responses, and the extinction of acquired fear.

Key words: memory; amygdala; classical conditioning; emotion; LTP; LTD; synaptic plasticity

basolateral nucleus of the amygdala (BLA) pathway in vivo (Maren and Fanselow, 1995). Most recently, auditory inputs from the thalamus (specifically the medial division of the medial geniculate nucleus) to the LA, a pathway involved in tone fear conditioning (LeDoux, 1994), were found to demonstrate an enhancement in auditory-evoked potentials (or LTP-like changes) after tone fear conditioning (Rogan and LeDoux, 1995; Rogan et al., 1997). Similarly, amygdalar slices prepared from animals that underwent fear conditioning exhibited increased synaptic transmission in the medial geniculate nucleus (MGN)-amygdala pathway (McKernan and Shinnick-Gallagher, 1997).

In contrast to its crucial involvement in the acquisition of fear conditioning, the role of the NMDA receptor on the expression of conditioned fear is unclear and disputed. Although some studies showed that intra-BLA inf usions of APV do not affect the expression of conditioned fear to the light-conditioned stimulus (CS) (Miserendino et al., 1990; Campeau et al., 1992), others found a significant effect to the context CS (Maren et al., 1996). Several factors may account for the discrepant effect of APV on the expression of conditioned fear. For instance, the fearpotentiated startle measure, in which the CR expression was not affected by APV, requires substantially more training (typically $\geq 10$ CS-unconditioned stimulus (US) pairings; Miserendino et al., 1990) than the freezing measure (typically one to three CS-US pairings; Maren et al., 1996), in which the CR expression was markedly affected by APV. Thus, the expression of strongly conditioned fear may be less susceptible to APV. Another possibility is that APV may have differential effects on different stimulus modalities used as CS. For example, the lack of performance effect of APV on fear-potentiated startle may be caused by discrete fear CSs (lights, tones) tested, whereas the effects of APV on freezing may be caused by diffuse contextual CS tested. One of the aims of this study, therefore, was to determine whether APV interferes with the expression of conditioned fear using 
training parameters similar to the fear-potentiated startle paradigm (experiment 2).

Recently it has been shown that previous learning protected animals from the amnesic effect of NMDA antagonists on new learning (of a similar behavioral task) (Bannerman et al., 1995; Saucier and Cain, 1995). For instance, Morris and colleagues found that if rats earlier learned a hidden platform task in the absence of APV, then they were able to learn a new hidden platform task (with different sets of spatial cues) in the presence of APV (Bannerman et al., 1995). Similarly, Saucier and Cain (1995) reported that rats pretrained on a nonspatial task were able to learn a hidden platform task with an NMDA receptor antagonist administration. This finding suggests that NMDA receptors may not be necessary for learning when similar types (or forms) of learning occurred beforehand. It is important to examine, then, whether APV affects the acquisition of fear conditioning to a CS in animals that were previously fear-conditioned to a different CS (experiment 1 ).

\section{EXPERIMENT 1A. AMYGDALAR NMDA RECEPTORS AND FEAR CONDITIONING IN PREVIOUSLY FEAR- CONDITIONED RATS: EFFECTS ON DISCRETE CS}

In this experiment, we examined whether intra-amygdalar infusions of APV block new CS-US association in rats that previously underwent fear conditioning to a different CS sans drug.

\section{Materials and Methods}

Subjects. Twenty experimentally naive adult male Long-Evans rats (270-300 gm) were individually housed in a climate-controlled vivarium with ad libitum access to food and water. All test procedures were conducted during the light phase of the cycle (7:00 A.M. to 7:00 P.M.).

Surgery. A stereotaxic instrument (Stoelting, Wood Dale, IL) was used to implant 26 gauge guide cannulae (Plastics One Inc., Roanoke, VA) in anesthetized rats $(30 \mathrm{mg} / \mathrm{kg}$ ketamine $\mathrm{HCl}$ and $2.5 \mathrm{mg} / \mathrm{kg}$ xylazine). Cannulae were implanted bilaterally into the BLA using the following coordinates: $2.3 \mathrm{~mm}$ posterior to the bregma, $5 \mathrm{~mm}$ lateral to the midline, and $7.7 \mathrm{~mm}$ ventral to the skull. Two animals did not survive from the surgery. During $7 \mathrm{~d}$ of postoperative recovery, rats were adapted to transportation and handling, and each dummy cannulae was removed and replaced with a clean one.

Drugs and injection. APV (Sigma, St. Louis, MO) was dissolved in artificial CSF (ACSF) and microinfused by backloading the drug up a 33 gauge internal cannulae into polyethylene tubing connected to $10 \mu \mathrm{l}$ Hamilton microsyringes. The internal cannulae extended $1.0 \mathrm{~mm}$ beyond the guide cannulae. An injection volume of $0.3 \mu \mathrm{l}$ was delivered using a Harvard PHD 2000 (Harvard Apparatus, Inc., South Natick, MA) syringe pump over the course of $3 \mathrm{~min}$.

Apparatus and procedure. Experiments used two modular operant test cages (both $27 \mathrm{~cm}$ width $\times 28 \mathrm{~cm}$ length $\times 30.5 \mathrm{~cm}$ height), equipped with speaker and house light modules (Coulbourn Instruments, Allentown, PA), located in an acoustic isolation room. The two cages differed in the following features: cage 1 had front and back walls made of Plexiglas and two side walls made of metal plates, whereas cage 2 had all four walls made of Plexiglas; cage 1 had tone and light modules on one side of the wall, whereas cage 2 had tone and light modules on the opposite side of the wall. The floors of both cages were composed of 16 stainless steel bars (4.5 mm diameter) spaced $17.5 \mathrm{~mm}$ center to center and wired to a Coulbourn precision-regulated animal shocker. The floor grid and base pan were washed thoroughly with tap water and completely dried before conditioning and testing.

On day 1 , animals were placed in either cage 1 or 2 with the following settings (trained context A): cages were wiped with $5 \%$ ammonium hydroxide solution, and the overhead room light was off, as was background white noise. After $1 \mathrm{~min}$, animals were presented with $10 \mathrm{co}-$ terminating light-footshock pairings (light, $10 \mathrm{sec} 28 \mathrm{~V}$ incandescent lamp for general illumination; footshock, $1 \mathrm{~mA}, 1 \mathrm{sec}$ ) with $1 \mathrm{~min}$ intertrial intervals (ITI). Animals were removed $1 \mathrm{~min}$ after the last shock and returned to their home cages.

On day 2, rats were infused with either APV (2.5 $\mu$ g per side) or ACSF and placed in the same chamber (context A) as on day 1. After $3 \mathrm{~min}$,

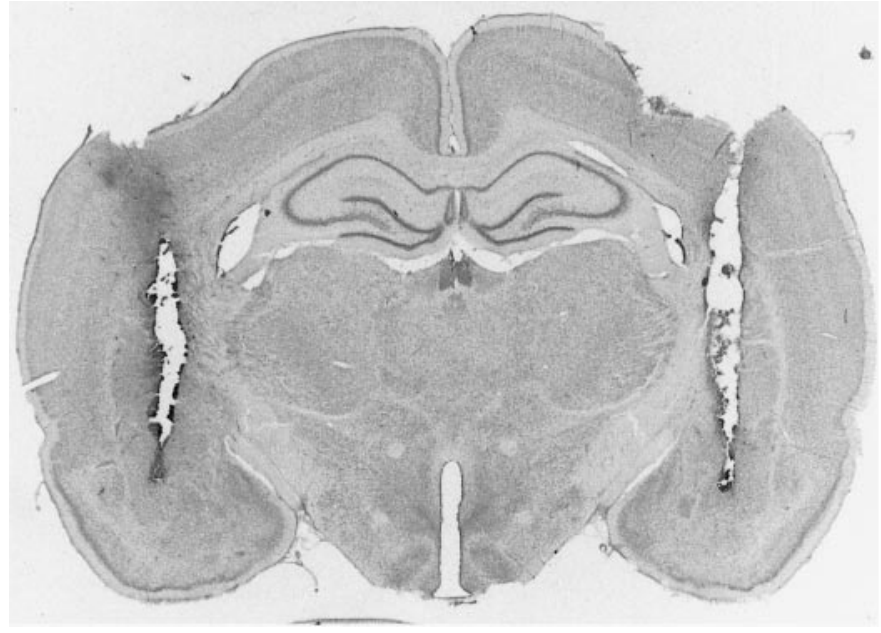

Figure 1. Photomicrograph showing a transverse brain section stained with cresyl violet from a rat with bilateral cannulae implanted in the basolateral nucleus of the amygdala.

three tone-footshock pairings were delivered (tone, $2.9 \mathrm{kHz}, 82 \mathrm{~dB}, 10$ $\mathrm{sec}$; footshock, $1 \mathrm{~mA}, 1 \mathrm{sec}$; $1 \mathrm{~min}$ ITI). One minute after the last shock animals were returned to their home cages.

On day 3 , animals were given a tone retention test in chambers that were different from days 1 and 2 in the following manner (shift context B): for both cages 1 and 2, the grid floor was entirely covered with a Plexiglas and sawdusts, cages were wiped with $30 \%$ ethanol, and animals that were trained in cage 1 were placed in cage 2 , and vice versa. These changes produce a very reliable context shift (see Results). [On context A days, animals were transported from the colony room to the laboratory in their plastic homecages $\left(21 \times 20 \times 42 \mathrm{~cm}^{3}\right.$; sawdust beddings on the floor), whereas on context $\mathrm{B}$ days, animals were transported in small wooden carrier boxes $\left(11 \times 12 \times 23 \mathrm{~cm}^{3}\right.$; wire mash floor.] The test consisted of $1 \mathrm{~min}$ baseline followed by $8 \mathrm{~min}$ of continuous tone.

On day 4 , animals were placed in the shift context B and, after 1 min baseline, presented with 8 min light retention test.

On day 5, animals were placed back in the trained context $\mathrm{A}$ for $8 \mathrm{~min}$ of context test.

Behavioral data collection. Data collection and stimulus presentations were controlled with an IBM-PC computer equipped with the Courbourn LabLinc Habitest Universal Linc System. A 24-cell infrared activity monitor that detects the movement of the emitted infrared $(1300 \mathrm{~nm})$ body heat image from the animal in the $x, y$, and $z$ axes was mounted on top of each cage and was used to assess freezing behavior. In brief, the total time of inactivity each animal exhibited was measured using a computer program, and freezing was defined as inactivity lasting $\geq 3 \mathrm{sec}$. Any behavior that yielded an inactivity of $<3 \mathrm{sec}$ was recorded as general activity. [Freezing scores obtained via infrared monitoring and observer time sampling methods (cf. Kim et al., 1991) consistently correlated higher than 0.92 (Pearson).]

Histology. At the completion of behavioral testing, the subjects were overdosed with ketamine $\mathrm{HCl}$ and xylazine and perfused intracardially with $0.9 \%$ saline followed by $10 \%$ buffered formalin. The brains were removed and stored in $10 \%$ formalin for at least 2 weeks before slicing. Transverse sections $(60 \mu \mathrm{m})$ were taken through the extent of the cannulae placement, mounted on gelatinized slides, and stained with cresyl violet dye. An observer unaware of the behavioral data determined the locations of the cannulae tips. A total of two rats were excluded from the statistical analysis because of incorrect cannulae placements.

\section{Results}

Figure 1 shows a photomicrograph of a transverse brain section stained with cresyl violet from a typical subject with bilateral cannulae implanted in the basolateral nucleus of the amygdala, and Figure 2 represents composite injection sites based on a reconstruction of cannulae placements in the BLA.

Figure 3 depicts the mean freezing level exhibited by APV and ACSF groups during $(A)$ day 1, 10 pairings of light-shock train- 


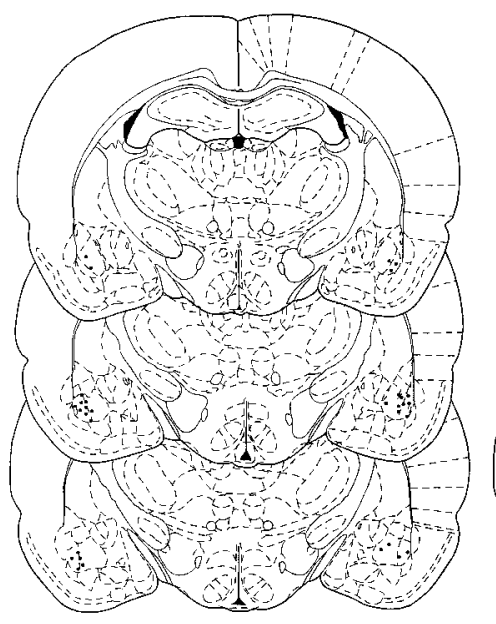

$\operatorname{Exp} 1 \mathrm{~A}$

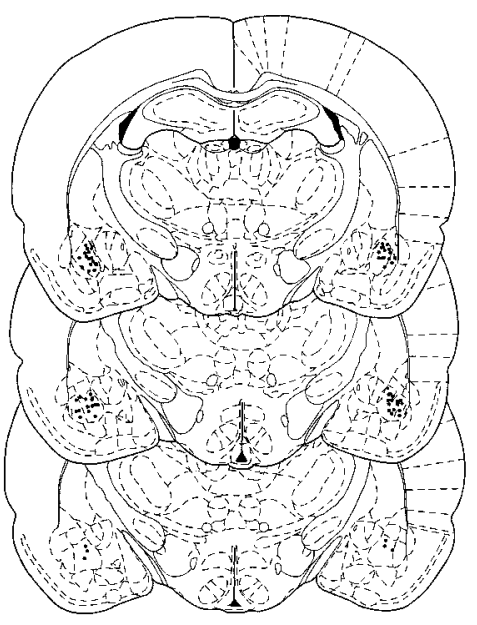

$\operatorname{Exp} 1 \mathrm{~B}$

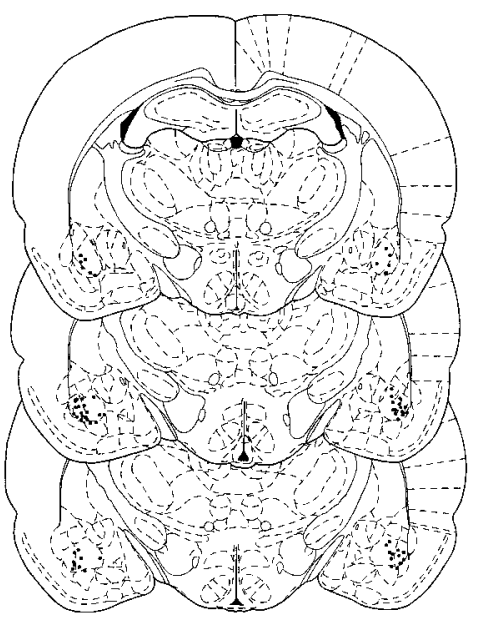

$\operatorname{Exp} 2$

Figure 2. Location of injection sites based on a reconstruction of cannulae placements in the BLA for experiments 1A (left panel), 1B (middle panel), and 2 (right panel).

ing in context $\mathrm{A} ;(B)$ day 2 , three pairings of tone-shock training in context $\mathrm{A} ;(C)$ day 3 , tone retention test in context $\mathrm{B} ;(D)$ day 4 , light retention test in context $\mathrm{B}$; and $(E)$ day 5 , context retention test in context A. On light-shock training day 1, freezing levels during the ITI were comparable between the two groups. Before the first shock, neither groups exhibited freezing. On day 2, animals that received ACSF into their BLA demonstrated freezing during the 3 min before tone-shock presentations. This freezing is caused by animals undergoing tone fear conditioning in the same chamber in which they received 10 light-shock pairings a day earlier. In contrast, when APV was infused into the BLA, the drug significantly impaired context freezing during the $3 \mathrm{~min}, F_{(1,14)}=11.02, p<0.01$; this effect on freezing seems to dissipate after the three tone-footshock presentations, $F_{(1,14)}=1.27, p>0.05$ (Fig. $3 B$ ).

It appears that APV infusions into the BLA blocked tone fear conditioning on day 2 because the APV group demonstrated significantly attenuated freezing to the tone CS on day 3 in comparison to the ACSF control group, $F_{(1,14)}=9.03, p<0.01$ (Fig. 3C). In APV-treated rats, there was no significant time effect on freezing during the first minute of pretone baseline and the subsequent $8 \mathrm{~min}$ of tone, $F_{(8,80)}=0.45, p=0.89$, whereas there was a significant time effect on freezing in ACSF-treated rats, $F_{(8,80)}=3.14, p<0.01$. In contrast to the tone test, conditioned freezing to the light (Fig. $3 D$ ) and the trained context (Fig. 3E), trained on day 1 in the absence of drug infusions, remained intact in the APV animals and did not differ from the ACSF control animals. Because freezing to the light CS did not differ between ACSF and APV groups, this indicates that tone conditioning did not generalize to the previously conditioned light in the ACSF animals. Together, these results indicate that APV selectively and completely blocked fear conditioning to a tone CS in animals that have previously been fear-conditioned to a light CS.

\section{EXPERIMENT 1B. AMYGDALAR NMDA RECEPTORS AND FEAR CONDITIONING IN PREVIOUSLY FEAR- CONDITIONED RATS: EFFECTS ON CONTEXTUAL CS}

Because the studies that demonstrated that pretrained rats appear to be protected from the APV-induced learning deficit used a spatial task (Bannerman et al., 1995; Saucier and Cain, 1995), in this experiment, we examined whether intra-BLA infusions of APV block fear conditioning to a new context in rats that acquired conditioned fear to a different context. It has been suggested that context learning is related to spatial learning and that both types of tasks depend on the hippocampus (O'Keefe and Nadel, 1978; Sutterland and Rudy, 1989).

\section{Materials and Methods}

Subjects, surgeries, and behavioral training. Four groups of naive male rats (Table 1) received bilateral cannulae implant surgery and drug inf usions in a manner identical to those in experiment $1 \mathrm{~A}$.

On day 1 , two of the four groups were placed in the experimental chamber A (same as described in experiment 1A) for 3 min, and then they received three footshocks $(1 \mathrm{~mA}, 1 \mathrm{sec}, 1 \mathrm{~min}$ apart). One minute after the last shock, the animals were returned to their home cages. The other two groups did not receive any training.

On day 2, the two groups that received training on day 1 were infused with either APV or ACSF bilaterally into the BLA. These groups then underwent identical fear conditioning in chamber B conditions (described in experiment 1A), except this time the shocks were delivered through the Courbourn mouse grid floor (composed of 26 bars spaced 11 $\mathrm{mm}$ apart). The other two groups, which did not receive training on day 1, were also infused with either APV or ACSF bilaterally into the BLA then underwent fear conditioning in chamber A settings.

On day 3, all four groups were given 8 min of context test in chamber B conditions.

On day 4, all four groups underwent 8 min of context test in chamber A conditions.

\section{Results}

Figure 2 depicts the injection sites based on reconstruction of cannulae placements in the BLA.

Figure 4 shows the freezing data from rats that were pretrained in context $\mathrm{A}$ and then underwent context $\mathrm{B}$ training with intraBLA inf usions of either APV or ACSF. As shown in Figure 4A, after 3 min baseline of no freezing, animals begin to exhibit freezing behavior subsequent to three footshocks. On day 2 (context training in chamber B) animals that received APV exhibited significantly less freezing than the animals that received ACSF during the 3 min before footshock presentation, $F_{(1,13)}=$ $47.70, p<0.01$. This freezing exhibited by the ACSF group is likely caused by context generalization effect, which is blocked in 

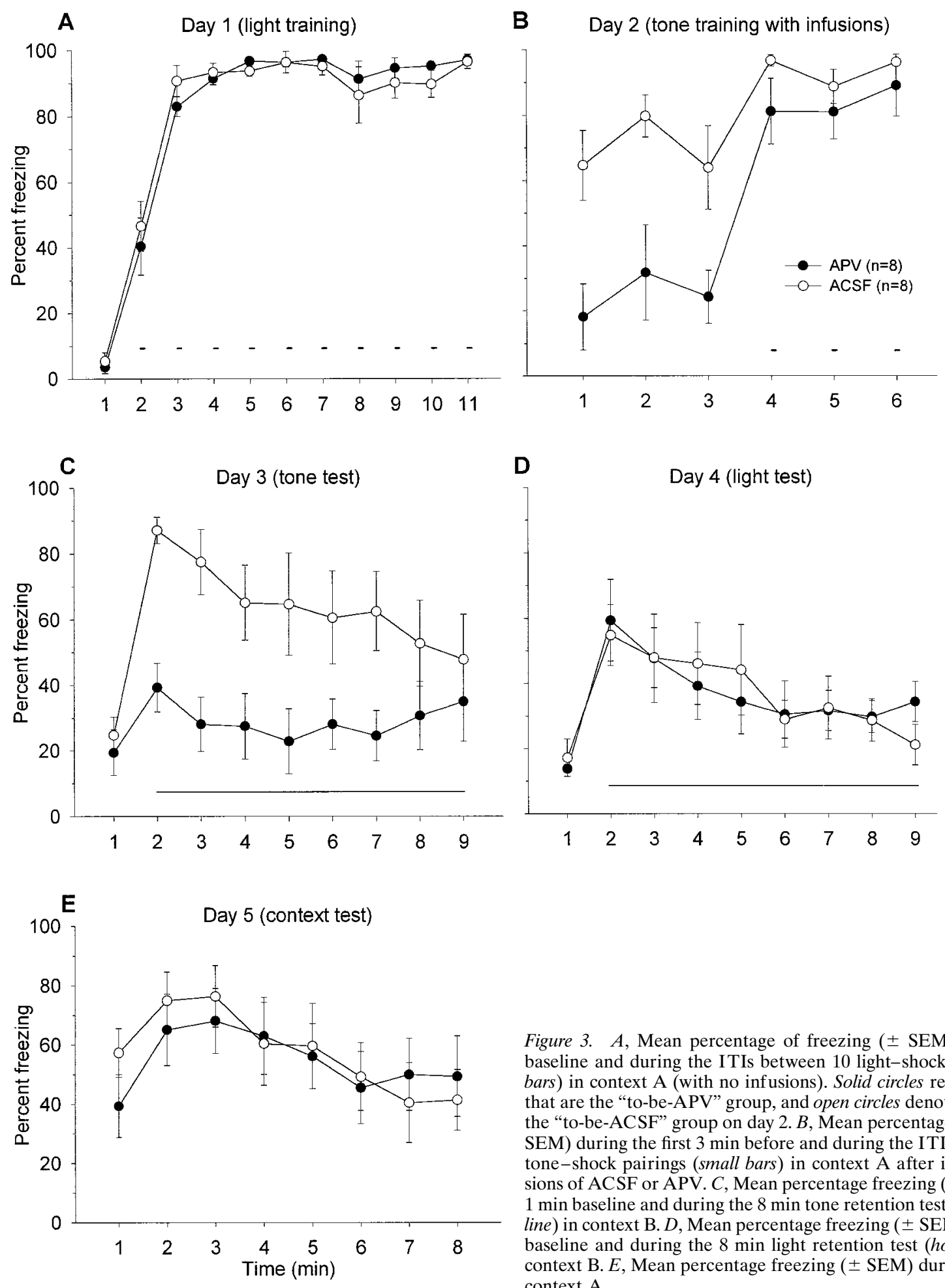

Figure 3. A, Mean percentage of freezing ( \pm SEM) during $1 \mathrm{~min}$ baseline and during the ITIs between 10 light-shock pairings (small bars) in context A (with no inf usions). Solid circles represent animals that are the "to-be-APV" group, and open circles denote those that are the "to-be-ACSF" group on day 2. B, Mean percentage of freezing ( \pm SEM) during the first 3 min before and during the ITIs between three tone-shock pairings (small bars) in context A after intra-BLA infusions of ACSF or APV. $C$, Mean percentage freezing ( \pm SEM) during $1 \mathrm{~min}$ baseline and during the $8 \mathrm{~min}$ tone retention test (long horizontal line $)$ in context B. $D$, Mean percentage freezing ( \pm SEM) during 1 min baseline and during the $8 \mathrm{~min}$ light retention test (horizontal line) in context B. $E$, Mean percentage freezing ( \pm SEM) during the 8 min in context A.

the presence of APV. (The freezing observed in context B before receiving footshocks is caused by a similarity in tactile information between the rat and mice grids, because in experiment $1 \mathrm{~A}$, when the floor was covered with Plexiglas and sawdusts, context generalization was not observed. It is important to note that, despite the fact that the grid floors were the main source of the context generalization, the use of grid floors was absolutely necessary to administer comparable footshocks and, thus, appropri- ate context generalization controls were included). After the shocks, the APV animals displayed enhanced freezing (minutes 4-6), but the freezing level was still below that of the ACSF animals, $F_{(1,13)}=5.71, p<0.05$.

When placed back in chamber B on day 3 (Fig. $4 C$ ), the animals that received ACSF infusions into their BLA on the previous day exhibited a significantly greater freezing than animals that received APV $, F_{(1,13)}=8.62, p<0.05$. The APV animals demon- 


\begin{tabular}{lllll}
\hline \multicolumn{4}{l}{ Table 1. Experimental design } \\
Group & Day 1 & Day 2 & Day 3 & Day 4 \\
\hline 1 & Trained in A & $\begin{array}{c}\text { Trained in B } \\
\text { with ACSF } \\
\text { Trained in B } \\
\text { with APV }\end{array}$ & Tested in B & Tested in A \\
& Trained in A & Tested in A \\
& & $\begin{array}{c}\text { Trained in A } \\
\text { with ACSF } \\
\text { Trained in A } \\
\text { with APV }\end{array}$ & Tested in B & Tested in A \\
& & & Tested in A \\
& & &
\end{tabular}

Animals in groups 1 and 2 undergo pretraining in chamber A before context conditioning in chamber B. Groups 3 and 4 are controls for the context generalization effect between chambers $\mathrm{A}$ and $\mathrm{B}$.

strate considerable freezing in chamber B, but a significant portion of this freezing was likely caused by context generalization from chamber A, evidenced by generalization effect controls (see below; Fig. 5B). When placed back in context A (Fig. 4D), both groups froze, but the freezing level was significantly higher in the ACSF group than the APV group, $F_{(1,13)}=8.69, p<0.05$. This difference is most likely caused by context $\mathrm{B}$ to A generalization effect in ACSF animals. Therefore, it appears that APV blocked the context $\mathrm{B}$ to $\mathrm{A}$ generalization effect (by completely blocking context B conditioning). In support of this view, the context A freezing level of APV animals (Fig. 4D) did not differ from the context A freezing level of ACSF animals that did not experience context B conditioning (Fig. $5 C$ ).

According to Figure $5 A$, animals that received intra-BLA infusions of APV (and presented with three footshocks in context A) exhibited a significant impairment in postshock freezing compared with ACSF-treated animals, $F_{(1,17)}=38.23, p<0.01$. On the following day, when placed in a different chamber $\mathrm{B}$, animals that received ACSF on the previous day (context A training) displayed freezing, whereas animals that received APV did not, $F_{(1,17)}=6.27, p<0.05$, indicating that there is a context generalization from chambers A to B in ACSF animals but not in APV animals (Fig. 5B). The context $\mathrm{B}$ freezing level (Fig. 5B) of animals that received ACSF before context A conditioning, (but never underwent context B conditioning) did not differ from the context $\mathrm{B}$ freezing level (Fig. $4 C$ ) of animals that received APV before context $\mathrm{B}$ conditioning, $F_{(1,15)}=1.84, p>0.05$. The APV animals did not freeze in context A (Fig. $5 C$ ) because APV completely blocked contextual fear conditioning in chamber A on day $1, F_{(1,17)}=5.75, p<0.05$.

In sum, these results indicate that intra-BLA inf usions of APV block contextual fear conditioning in rats that were pre-fearconditioned to a different context.

\section{EXPERIMENT 2. ARE NMDA RECEPTORS INVOLVED IN THE EXPRESSION OF CONDITIONED FEAR?}

In both experiments $1 \mathrm{~A}$ and $1 \mathrm{~B}$, intra-amygdalar infusions of APV significantly impaired the expression of conditioned fear to the context as measured by freezing response during $3 \mathrm{~min}$ of baseline. To determine whether the effect of APV on conditioned freezing was specific to context cues, experiment 2 administered APV after fear conditioning to discrete cues: tones and lights.

\section{Materials and Methods}

Subjects, surgery, and drug injection. Forty naive adult male Long-Evans rats (270-300 $\mathrm{gm})$ served as subjects. The surgical and drug preparation and delivery procedures were identical to those of experiment 1A. One subject did not survive the surgery.
Apparatus and procedure. Training and testing took place in the two chambers described in experiment $1 \mathrm{~A}$, except that background noise was on in chamber A for light groups, and room lights were on in chamber B for tone groups. Animals were randomly assigned to two groups. On day 1 , one group received 10 tone-shock pairings ( $10 \mathrm{sec}$ tone coterminating with $1 \mathrm{sec}$ footshock; ITI, $1 \mathrm{~min})$, and the other group received 10 light-shock pairings (10 sec light coterminating with 1 sec footshock; ITI, $1 \mathrm{~min}$ ), both in chamber A. On day 2, half of the animals from each group received APV and the other half received ACSF and were then placed in chamber A for 8 min of context test. On day 3, they were placed back in chamber A for $8 \mathrm{~min}$, this time without any inf usions (to assess whether APV affects context extinction on day 2). On day 4, the animals that received APV on day 2 were infused with ACSF and vice versa. Then, they were given either tone or light retention test in chamber B. On day 5, animals were given the same test as day 4 without any drug infusions (to test whether APV affects either tone or light extinction on day 4).

\section{Results}

Figure 2 depicts the injection sites based on a reconstruction of cannulae placements in the BLA. Four animals were excluded from the statistical analysis because of incorrect cannulae placements.

Figures 6 and 7 show freezing data from light-shock-trained animals and tone-shock-trained animals, respectively.

As shown in Figures $6 A$ and $7 A$, animals show postshock freezing during the ITIs on day 1 of training. On day 2, when animals were given context test under the influence of APV, they showed a significantly attenuated freezing in comparison to the animals that received ACSF, in both light-shock-trained animals, $F_{(1,16)}=13.53, p<0.01$ (Fig. $6 B$ ) and tone-shock-trained animals, $F_{(1,15)}=6.56, p<0.05$ (Fig. $7 B$ ). On day 3 , when retested in the same context, there was a trend showing that the animals that received APV on day 2 froze more than those animals that received ACSF on day $2\left[F_{(1,16)}=3.12, p=0.10\right.$ for the lightshock-trained groups (Fig. $6 C$ ); $F_{(1,15)}=3.33, p=0.08$ for the tone-shock-trained groups (Fig. $7 C$ )], probably because of impaired extinction in APV animals. This observation is supported by significant interaction effects between the drug treatment and the testing day $\left[F_{(1,32)}=12.92, p<0.01\right.$ for the light-shocktrained groups (Fig. $6 C$, inset); $F_{(1,30)}=9.12, p<0.01$ for the tone-shock-trained groups (Fig. $7 C$, inset)]. On day 4 , the animals that received APV before light (Fig. 6D) or tone (Fig. $7 D$ ) retention test demonstrated significantly less freezing than ACSF animals [light, $F_{(1,16)}=13.37, p<0.01$; tone, $F_{(1,15)}=21.82, p<$ $0.01]$. When retested to light or tone without any infusions, the animals that received APV on the previous tone test (day 4) froze considerably more than the animals that received ACSF on the previous tone test, $F_{(1,15)}=23.11, p<0.01$ (Fig. $7 E$ ). No difference was observed for the second light test, but there was a significant drug treatment $\times$ testing day interaction, $F_{(1,32)}=$ 6.07, $p<0.05$ (Fig. $6 E$, inset). Thus, these results indicate that intra-BLA infusions of APV block expression of the conditioned freezing response to the tone, light, and context stimuli, and also seem to impede extinction.

\section{DISCUSSION}

In the first study (experiment 1A), we found that intra-amygdalar infusions of a competitive NMDA receptor antagonist APV completely blocked fear conditioning to the tone CS in animals previously fear-conditioned to the light CS (under normal conditions). However, they demonstrated freezing to the light CS and to the context in which the light CS and the footshock US were paired, indicating that APV did not produce damage in the BLA. Control animals that received vehicle (ACSF) just before the 

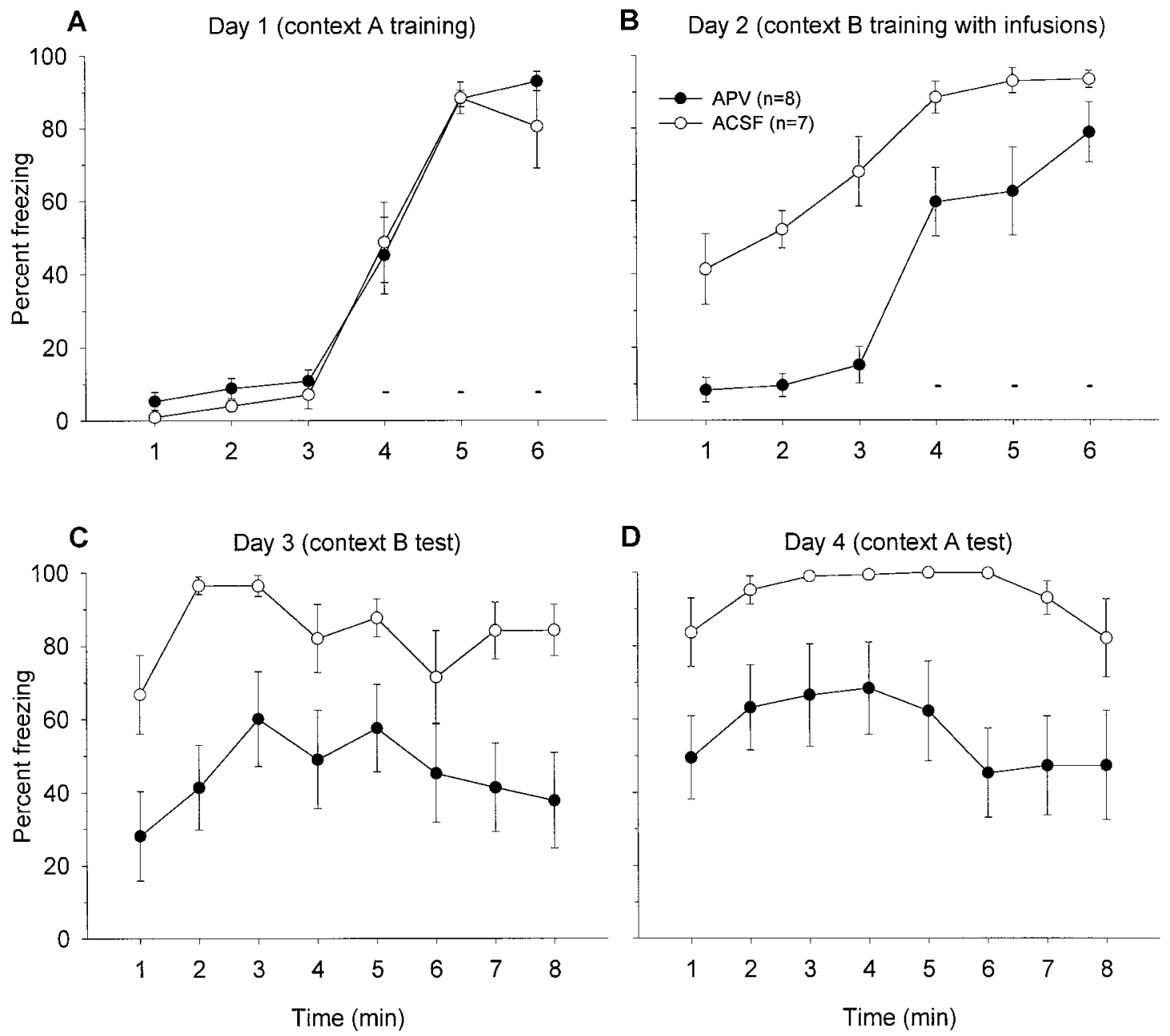

Figure 4. A, Mean percentage of freezing ( \pm SEM) 3 min before and during the ITIs amid three footshocks (small bars) in context A (no infusions). Solid circles are to-be-APV, and open circles are to-be-ACSF groups on day 2. B, Mean percentage of freezing ( \pm SEM) demonstrated by ACSF- and APV-treated rats 3 min before and during the ITIs between three shocks (small bars) in context B. $C$, Mean percentage of freezing ( \pm SEM) during 8 min in context B. $D$, Mean percentage of freezing ( \pm SEM) during 8 min in context A.

tone fear-conditioning phase demonstrated freezing to all CS modalities (light, context, and tone) tested. Similarly, intraamygdalar infusions of APV blocked new contextual fear conditioning in animals formerly fear-conditioned to a different context (experiment 1B). The fact that APV blocked new fear conditioning in previously fear-conditioned animals indicates that NMDA receptors are critical for specific learning (i.e., formation of particular CS-US associations) that occurs during fear conditioning.

One may speculate that NMDA receptors can be sensitive to specific state (i.e., the presence of drug) when the learning occurs, and, thus, the deficit of new fear learning is caused by the absence of APV during testing. However, both Maren et al. (1996) and Miserendino et al. (1990) manipulated the drug states during training and testing and showed that there was no statedependent effect of APV on freezing and fear-potentiated startle responses. Thus, the possibility of state-dependent effect of APV can be ruled out. The possibility of APV affecting sensitivity to footshock can also be excluded based on earlier studies that found that APV does not compromise pain sensitivity (Miserendino et al., 1990; Kim et al., 1991; Maren et al., 1996).

In spatial learning, it has been reported that rats pretrained in a different water maze (without APV) were able to learn a new water maze in the presence of APV (Bannerman et al., 1995). In contrast, we find that intra-BLA infusions of APV significantly blocked new fear learning to either a discrete (tone) CS or a diffuse (context) CS in rats that were previously fear-conditioned to either a light CS or a different context CS. It is possible that the lack of APV-induced spatial learning deficit in pretrained animals may be, in part, caused by a task generalization between the two different water mazes. For instance, animals that were pretrained in a water maze appear to exhibit a faster learning rate in a different water maze than animals that were not pretrained (Bannerman et al., 1995), suggesting there may be savings. Consistent with this view is the fact animals that were pretrained in a water maze with curtains drawn, in which there is less task generalization, failed to learn a new water maze task in the presence of APV (Bannerman et al., 1995). Also, in naive animals NMDA receptor antagonists block de novo spatial learning (Bannerman et al., 1995; Saucier and Cain, 1995). In our contextual fearconditioning experiment, we found that although the two contexts were extensively different (in visual, auditory, and olfactory domains), there was a considerable level of contextual generalization between the two contexts (because of the grid floor necessary to administer the footshock). In the absence of generalization 

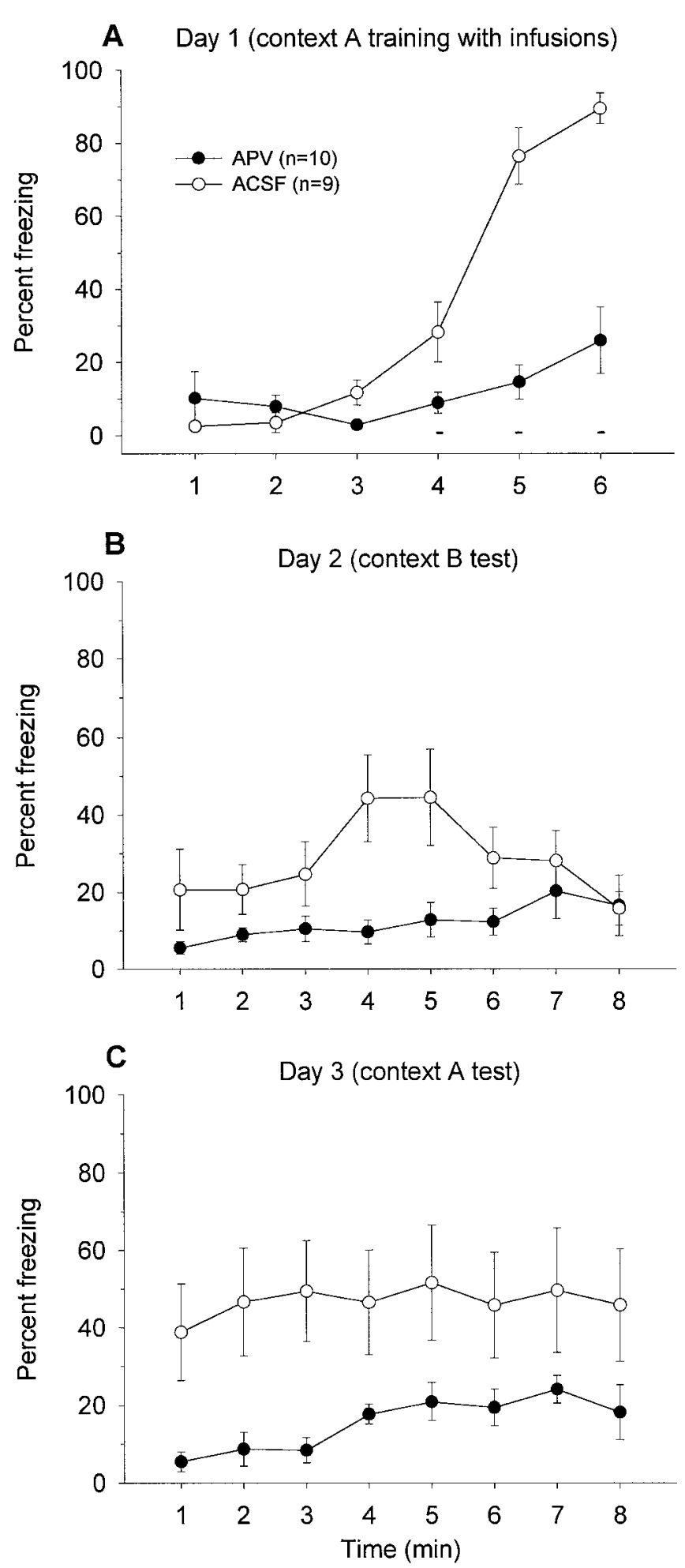

Figure 5. A, Mean percentage of freezing ( \pm SEM) 3 min before and during the ITIs between three shocks (small bars) in context A after intra-BLA infusions of ACSF or APV. $B$, Mean percentage of freezing $( \pm \mathrm{SEM})$ during $8 \mathrm{~min}$ in context B. $C$, Mean percentage of freezing $( \pm$ SEM) during $8 \mathrm{~min}$ in context $\mathrm{A}$.

controls (Fig. 5), our results also look as though contextual fear conditioning can occur in the presence of APV in rats previously fear-conditioned to a different context (Fig. 4C). However, the possibility of context generalization "masking" new context learn- ing in the presence of APV cannot be completely excluded. Nonetheless, when discrete CSs (i.e., tone and light) from different sensory modalities were used, there was no generalization effect, and APV completely blocked new fear learning in previously fear-conditioned rats. Other differences between the water maze and fear-conditioning tasks (e.g., emotional vs spatial learning, fast vs gradual learning, different brain sites of the drug action, etc.) may also contribute to contrasting results.

When infused directly into the BLA, APV significantly impaired the expression of conditioned fear, as measured by the freezing response. This was clearly observed in relation to various fear CSs (tone, light, and context) tested, effectively ruling out the possibility that the effect of APV on the expression of conditioned fear is selective to CS modality. Moreover, because animals received overtraining of fear conditioning (apropos freezing) in the present study (comparable to that of the fear-potentiated startle paradigm), the discrepancy in the effect of APV on the expression of conditioned fear was not caused by differences in the magnitude of conditioned fear. Intra-BLA inf usions of APV also blocked postshock freezing in naïve animals (Fig. $5 A$ ). However, this effect was not evident in APV groups that previously underwent fear conditioning (Figs. 3B, 4B), possibly because of either a ceiling effect in freezing of ACSF animals or that pretraining on a similar fear-conditioning task preventing the postshock freezing deficit induced by APV infusions. When retested for the expression of conditioned fear, consistent with earlier reports (Falls et al., 1992), animals that received APV during the previous CS-alone extinction trials exhibited greater freezing than those that received ACSF during the previous CS-alone extinction trials. This finding indicates that intra-BLA infusions of APV seem to attenuate the extinction of acquired fear.

What is the basis, then, for APV affecting the expression of conditioned fear as measured by the freezing response (this study; Maren et al., 1996) but not the expression of conditioned fear as measured by the startle response (Miserendino et al., 1990; Campeau et al., 1992; Gewirtz and Davis, 1997)? It has been suggested that BLA-LA nuclei are the "CS-US association" centers that send projections to the motor output region of the amygdala (i.e., the central nucleus) (Lavond et al., 1993; Davis, 1994; LeDoux, 1994; Maren and Fanselow, 1996). The central nucleus of the amygdala in turn projects to specific brain regions that mediate specific fear responses, such as changes in autonomic responses (e.g., the lateral nucleus of the hypothalamus for the heart rate; LeDoux et al., 1988), analgesia (the ventral periaqueductal gray, vPAG; Helmstetter and Landeira-Fernandez, 1990; Helmstetter and Tershner, 1994), startle (the nucleus reticularis pontis caudalis; Davis, 1992), and freezing (the vPAG; LeDoux et al., 1988; Kim et al., 1993). If so, APV in the amygdala should affect the expression of fear CRs in a similar manner, that is, the expression of conditioned freezing and potentiated startle should be similarly affected by APV. One possibility that can account for this difference is that APV in the BLA increases the motor activity such that animals do not freeze. In contrast to freezing (measured in minutes), the potentiated startle may not be affected by APV because the startle response is measured in a much narrower time range (e.g., 200 msec; Campeau et al., 1992). However, we did not observe an enhancement in motor activity after local infusions of APV into the BLA, e.g., the pre-CS baseline activity did not differ from the ACSF controls. Moreover, APV animals did demonstrate postshock freezing behavior (Figs. 3B, 4B). Another possibility is that there may be a divergence of CR centers within the amygdala (Fig. 8). For instance, there might be rapid and 

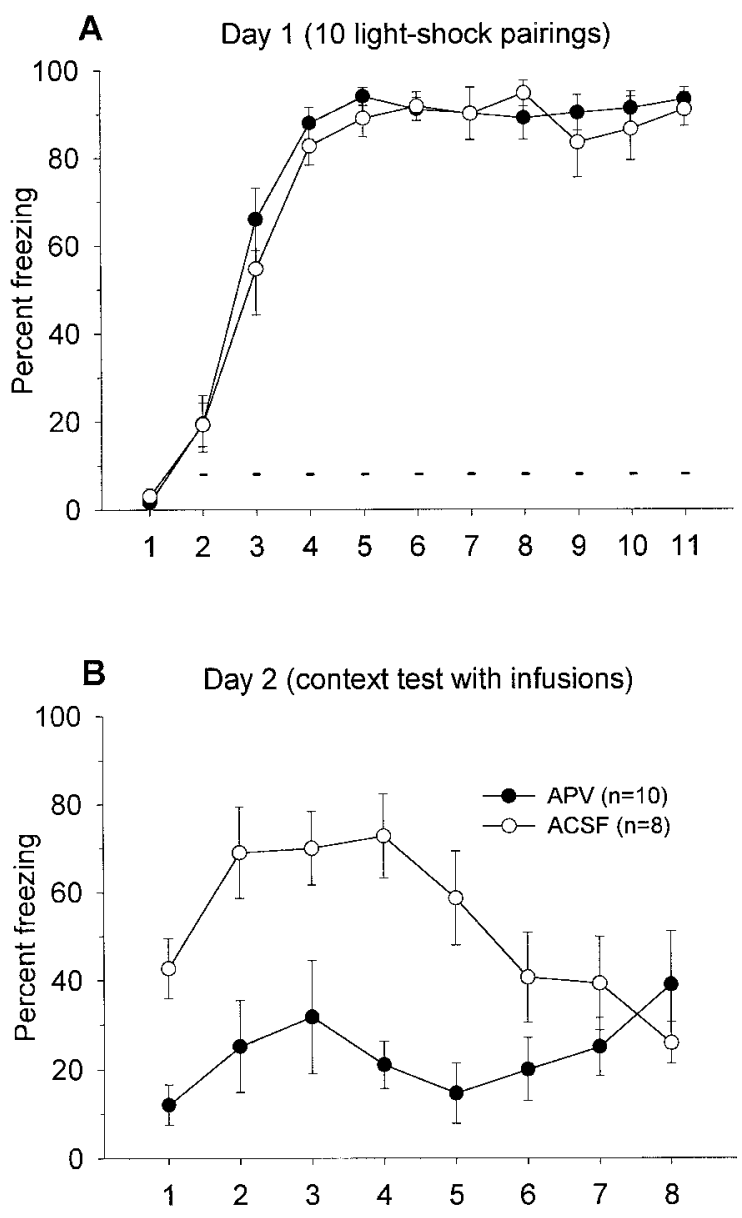

C Day 3 (context test without infusions)
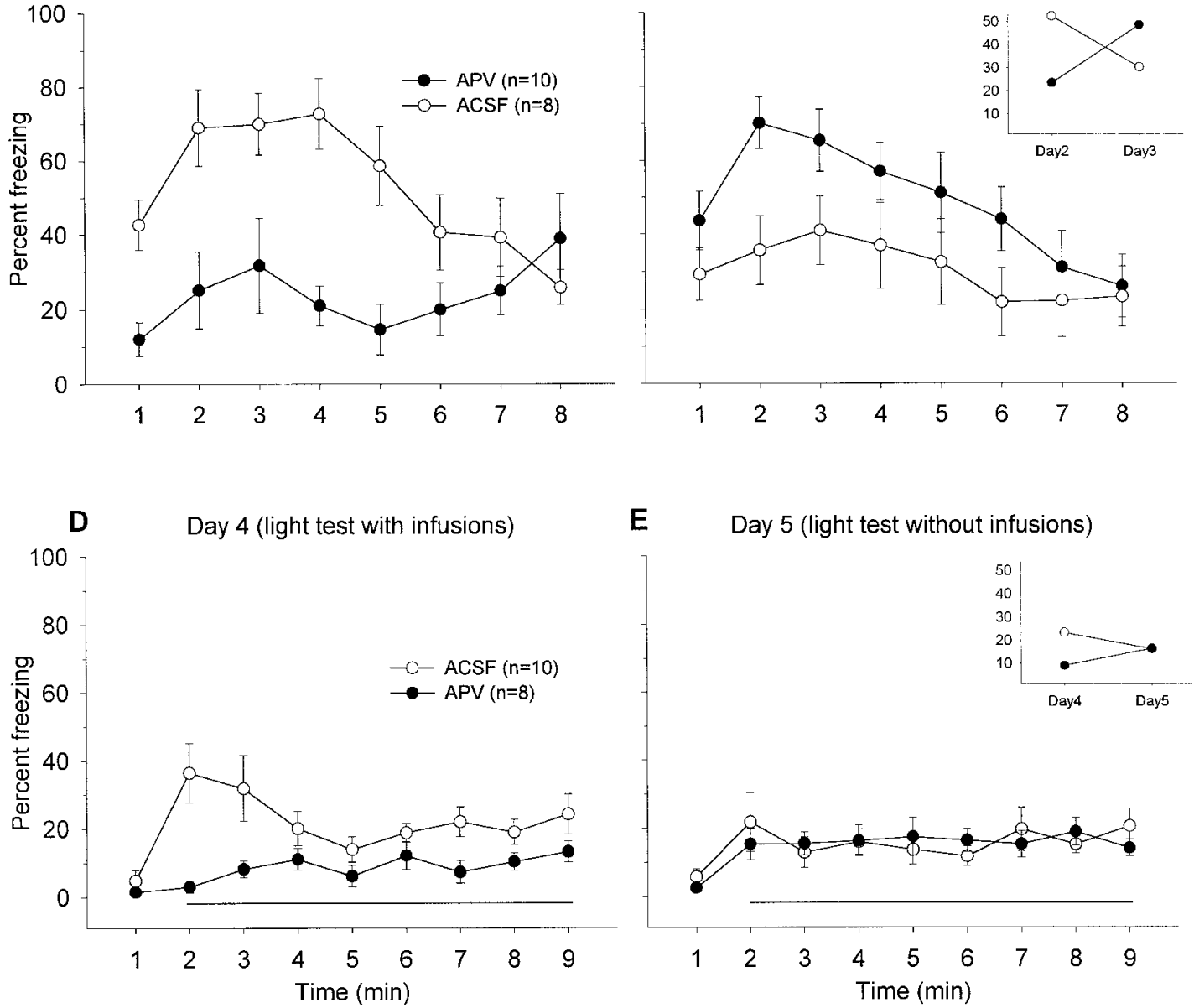

Figure 6. $A$, Mean percentage of freezing ( \pm SEM) 1 min before and during the ITIs intervening 10 light-shock pairings (small bars) in context A (with no inf usions). Solid circles are to-be-APV, and open circles are to-be-ACSF groups on day 2. $B$, Mean percentage of freezing ( \pm SEM) during 8 min in context A after intra-BLA infusions of ACSF or APV. C, Mean percentage of freezing ( \pm SEM) during the 8 min extinction test in context A. Inset, Mean percentage of freezing exhibited by APV and ACSF groups during the 8 min context tests on days 2 and 3. $D$, Mean percentage of freezing ( \pm SEM) 1 min before and during 8 min light retention test (horizontal line) in context B after intra-BLA infusions of either ACSF or APV. E, Mean percentage of freezing ( \pm SEM) during light extinction test in context B. Inset, Mean percentage of freezing displayed by APV and ACSF groups during the 8 min light tests on days 4 and 5 .

gradual fear motor centers that mediate different fear CRs. The rapid center will be activated with few fear conditioning trials and mediate fear responses such as freezing, analgesia, and changes in autonomic responses. In contrast, the activation of the gradual center requires much more fear-conditioning trials and mediate relatively well-timed fear responses such as the potentiated startle response. One can then speculate that the difference on the expression of conditioned freezing and potentiated startle with 

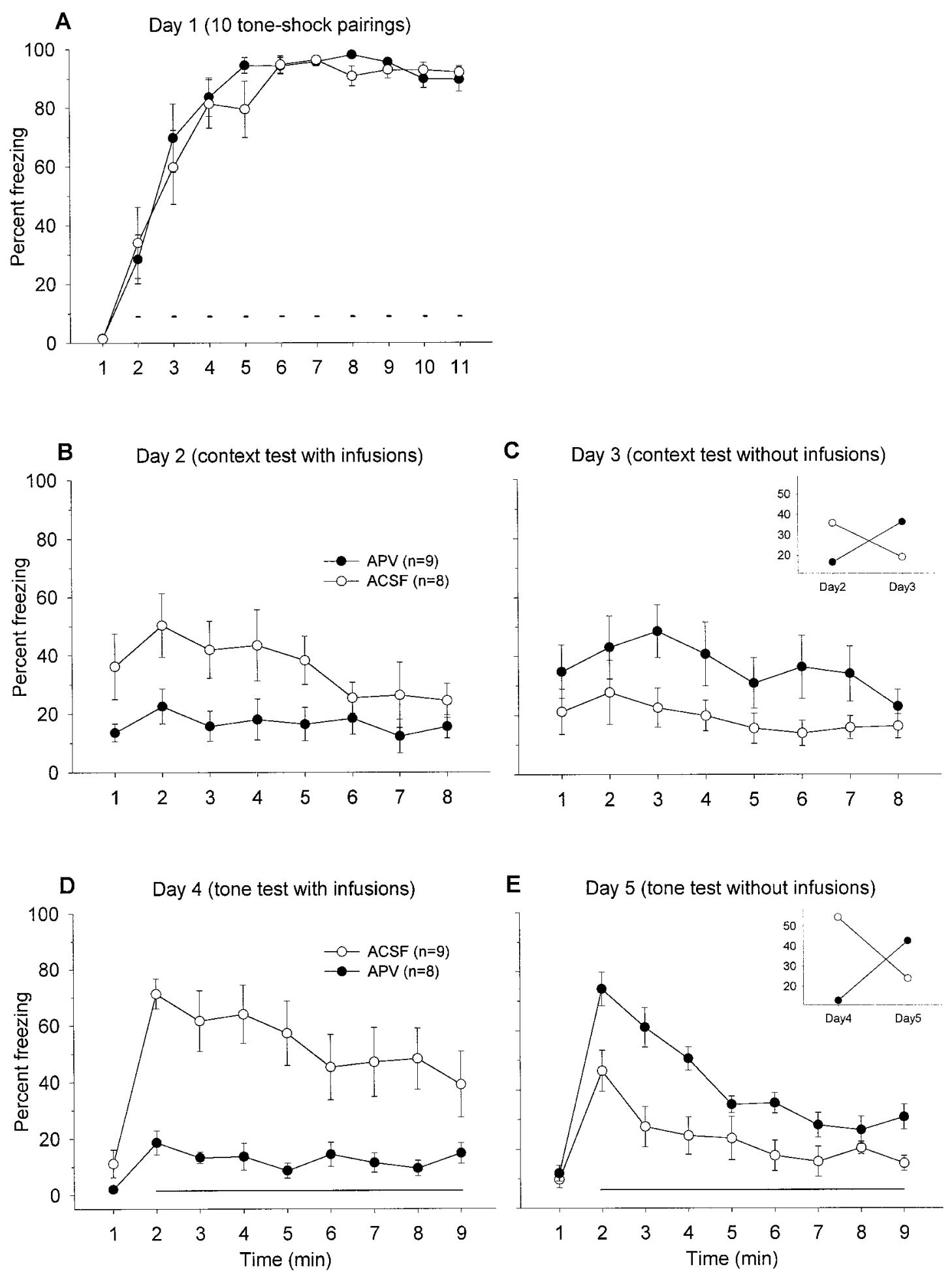

Figure 7. A, Mean percentage of freezing ( \pm SEM) during 1 min before and during the ITIs between 10 tone-shock pairings (small bars) in context A with no inf usions. $B$, Mean percentage of freezing ( \pm SEM) during 8 min in context A after intra-BLA inf usions of either ACSF or APV. $C$, Mean percentage of freezing $( \pm$ SEM) during 8 min extinction test in context A. Inset, Mean percentage freezing exhibited by APV and ACSF groups during the 8 min context tests on days 2 and 3. D, Mean percentage of freezing ( \pm SEM) during tone retention test in context B after intra-BLA infusions of either ACSF or APV. E, Mean percentage of freezing ( \pm SEM) during tone extinction test in context B. Inset, Mean percentage freezing displayed by APV and ACSF groups during the 8 min tone tests on days 4 and 5.

APV may be caused by the NMDA receptor involvement in the synaptic transmission mediating the expression of conditioned freezing but not potentiated startle. In addition to affecting the expression of conditioned freezing, APV also seems to markedly disrupt the expression of inhibitory avoidance learning (Kim, 1991; but see Liang et al., 1994), a fear-conditioning task that is also rapidly acquired (e.g., with one trial). One way to test whether there are different amygdalar fear motor centers that 


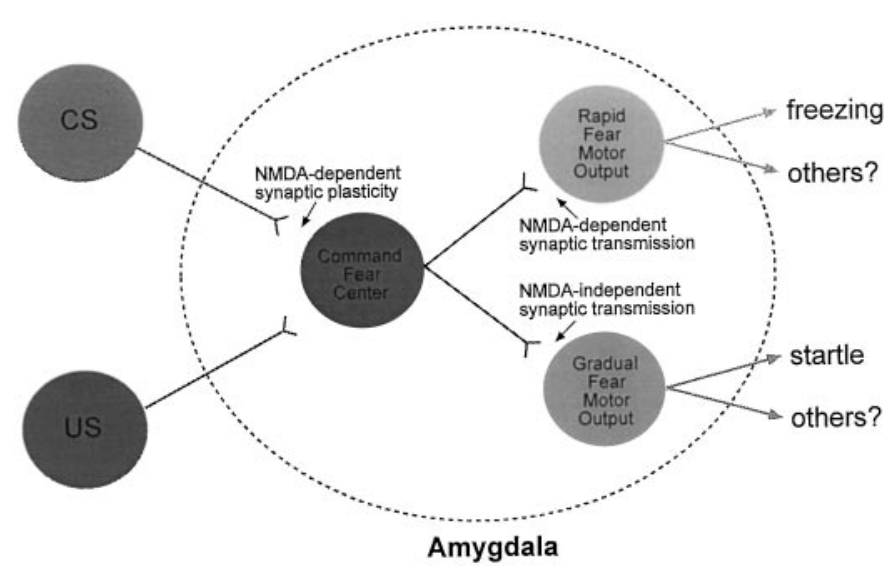

Figure 8. A hypothetical diagram of how NMDA receptors in the amygdala may be differentially involved in the synaptic transmission mediating the expression of conditioned freezing and potentiated startle responses.

mediate different fear responses is to inject different retrograde tracers into, for example, the nucleus reticularis pontis caudalis (which mediate the startle response) and the vPAG (which mediate the freezing response), and determine whether different sets of amygdalar neurons are labeled.

In the hippocampus (e.g., the Schaffer collateral/commissuralCA1 pathway), the NMDA receptor antagonists have been found to block the induction of LTP, and the normal synaptic transmission is relatively unaffected (Collingridge and Bliss, 1995). Although fear conditioning seems to involve NMDA receptors in the amygdala, there is no evidence that NMDA receptors are involved in the amygdalar LTP in the manner shown in the hippocampus. In an earlier study, the APV concentration required to block the induction of LTP in the amygdala also markedly impaired normal synaptic transmission (Chapman and Bellavance, 1992). At lower concentrations at which normal synaptic transmission was unaffected, APV had no effect on the induction of LTP (Chapman and Bellavance, 1992). A recent study also failed to block amygdalar LTP with APV, but shortterm potentiation was blocked by APV (Li et al., 1998). Correspondingly, a single-unit recording study indicates that the normal auditory-evoked response in the amygdala is attenuated by APV, suggesting that the NMDA receptors are involved in the normal synaptic transmission of the MGN-LA pathway that mediates auditory fear conditioning ( $\mathrm{Li}$ et al., 1995). Thus, it is not known whether the APV concentration required to block fear conditioning selectively blocks the amygdalar LTP (or other forms of long-lasting synaptic plasticity) induction without affecting normal synaptic transmission in a manner demonstrated in the hippocampal CA1 region (Collingridge and Bliss, 1995). [Typically, a single test pulse stimulation is used to evaluate the effect of APV on "normal" synaptic transmission. However, this is an artificial stimulation condition for assessing synaptic transmission. Temporal dynamics of different stimulation patterns will considerably alter the synaptic transmission property (Gerstner et al., 1997) and, accordingly, APV may influence synaptic transmission under different stimulation conditions.] Clearly, additional experiments involving different APV concentrations on amygdalar LTP and normal synaptic transmission (of different pathways) are needed to further describe the role of NMDA receptors in fear conditioning.

In summary, NMDA receptors in the BLA are crucial for the encoding of conditioned fear to both discrete CS and contextual
CS in both naive and previously fear-conditioned rats. NMDA receptors in BLA also seem to be critical for the expression of conditioned fear, irrespective of the CS modality and the fear level, and they interfere with the extinction of acquired fear.

\section{REFERENCES}

Bannerman DM, Good MA, Butcher SP, Ramsay M, Morris RG (1995) Distinct components of spatial learning revealed by previous training and NMDA receptor blockade. Nature 378:182-186.

Bear MF, Malenka RC (1994) Synaptic plasticity: LTP and LTD. Curr Opin Neurobiol 4:389-399.

Campeau S, Miserendino MJ, Davis M (1992) Intra-amygdala infusion of the $N$-methyl-D-aspartate receptor antagonist AP5 blocks acquisition but not expression of fear-potentiated startle to an auditory conditioned stimulus. Behav Neurosci 106:569-574.

Chapman PF, Bellavance LL (1992) Induction of long-term potentiation in the basolateral amygdala does not depend on NMDA receptor activation. Synapse 11:310-318.

Chapman PF, Kairiss EW, Keenan CL, Brown TH (1990) Long-term synaptic potentiation in the amygdala. Synapse 6:271-278.

Clugnet MC, LeDoux JE (1990) Synaptic plasticity in fear conditioning circuits: induction of LTP in the lateral nucleus of the amygdala by stimulation of the medial geniculate body. J Neurosci 10:2818-2824.

Collingridge GL, Bliss TV (1995) Memories of NMDA receptors and LTP. Trends Neurosci 18:54-56.

Davis M (1992) The role of the amygdala in fear and anxiety. Annu Rev Neurosci 15:353-375.

Davis M (1994) The role of the amygdala in emotional learning. Int Rev Neurobiol 36:225-266.

Falls WA, Miserendino MJ, Davis M (1992) Extinction of fearpotentiated startle: blockade by infusion of an NMDA antagonist into the amygdala. J Neurosci 12:854-863.

Fanselow MS, Kim JJ (1994) Acquisition of contextual Pavlovian fear conditioning is blocked by application of an NMDA receptor antagonist D,L-2-amino-5-phosphonovaleric acid to the basolateral amygdala. Behav Neurosci 108:210-212.

Gerstner W, Kreiter AK, Markram H, Herz AVM (1997) Neural codes: firing rates and beyond. Proc Natl Acad Sci USA 94:12740-12741.

Gewirtz JC, Davis M (1997) Second-order fear conditioning prevented by blocking NMDA receptors in amygdala. Nature 388:471-474.

Helmstetter FJ, Landeira-Fernandez J (1990) Conditional hypoalgesia is attenuated by naltrexone applied to the periaqueductal gray. Brain Res 537:88-92.

Helmstetter FJ, Tershner SA (1994) Lesions of the periaqueductal gray and rostral ventromedial medulla disrupt antinociceptive but not cardiovascular aversive conditional responses. J Neurosci 14:7099-7108.

Huang YY, Kandel ER (1997) Bidirectional modification of PKA on synaptic plasticity in the lateral amygdala. Soc Neurosci Abstr 23:469.13.

Kim JJ, DeCola JP, Landeira-Fernandez J, Fanselow MS (1991) $N$-methyl-D-aspartate receptor antagonist APV blocks acquisition but not expression of fear conditioning. Behav Neurosci 105:126-133.

Kim JJ, Rison RA, Fanselow MS (1993) Effects of amygdala, hippocampus, and periaqueductal gray lesions on short- and long-term contextual fear. Behav Neurosci 107:1093-1098.

Kim M (1991) NMDA receptors in the amygdala in learning and memory. PhD dissertation, University of California, Irvine.

Kim M, McGaugh JL (1992) Effects of intra-amygdala injections of NMDA receptor antagonists on acquisition and retention of inhibitory avoidance. Brain Res 585:35-48.

Lavond DG, Kim JJ, Thompson RF (1993) Mammalian brain substrates of aversive classical conditioning. Annu Rev Psychol 44:317-342.

LeDoux JE (1993) Emotional memory: in search of systems and synapses. Ann NY Acad Sci 702:149-157.

LeDoux JE (1994) Emotion, memory and the brain. Sci Am 270:50-57.

LeDoux JE, Iwata J, Cicchetti P, Reis DJ (1988) Different projections of the central amygdaloid nucleus mediate autonomic and behavioral correlates of conditioned fear. J Neurosci 8:2517-2529.

Li H, Weiss SRB, Chuang D, Post RM, Rogawski MA (1998) Bidirectional synaptic plasticity in the rat basolateral amygdala: characterization of an activity-dependent switch sensitive to the presynaptic metabotropic glutamate receptor antagonist $2 S$ - $\alpha$-ethylglutamic acid. J Neurosci 18:1662-1670. 
Li XF, Phillips R, LeDoux JE (1995) NMDA and non-NMDA receptors contribute to synaptic transmission between the medial geniculate body and the lateral nucleus of the amygdala. Exp Brain Res 105:87-100.

Liang KC, Hon W, Davis M (1994) Pre- and posttraining infusion of $N$-methyl-D-aspartate receptor antagonists into the amygdala impair memory in an inhibitory avoidance task. Behav Neurosci 108:241-253.

Maren S, Fanselow MS (1995) Synaptic plasticity in the basolateral amygdala induced by hippocampal formation stimulation in vivo. J Neurosci 15:7548-7564.

Maren S, Fanselow MS (1996) The amygdala and fear conditioning: has the nut been cracked? Neuron 16:237-240.

Maren S, Aharonov G, Stote DL, Fanselow MS (1996) N-methyl-Daspartate receptors in the basolateral amygdala are required for both acquisition and expression of conditional fear in rats. Behav Neurosci 110:1365-1374.

McGaugh JL, Introini-Collison IB (1987) Hormonal and neurotransmitter interactions in the modulation of memory storage: involvement of the amygdala. Int J Neurol 21-22:58-72.

McGaugh JL, Cahill L, Roozendaal B (1996) Involvement of the amyg dala in memory storage: interaction with other brain systems. Proc Natl Acad Sci USA 93:13508-13514.

McKernan MG, Shinnick-Gallagher P (1997) Fear conditioning induces a lasting potentiation of synaptic currents in vitro. Nature 390:607-611.

Miserendino MJ, Sananes CB, Melia KR, Davis M (1990) Blocking of acquisition but not expression of conditioned fear-potentiated startle by NMDA antagonists in the amygdala. Nature 345:716-718.

O'Keefe J, Nadel L (1978) The hippocampus as a cognitive map. Oxford: Clarendon.

Rogan MT, LeDoux JE (1995) LTP is accompanied by commensurate enhancement of auditory-evoked responses in a fear conditioning circuit. Neuron 15:127-136.

Rogan MT, Staubli UV, LeDoux JE (1997) Fear conditioning induces associative long-term potentiation in the amygdala. Nature 390:604-607.

Saucier D, Cain DP (1995) Spatial learning without NMDA receptordependent long-term potentiation. Nature 378:186-189.

Sutherland RJ, Rudy JW (1989) Configural association theory: the role of the hippocampal formation in learning, memory, and amnesia. Psychobiology 17:129-144. 